\title{
Vectorial status and insecticide resistance of Anopheles funestus from a sugar estate in southern Mozambique
}

\author{
R Graham Kloke ${ }^{1,2,3}$, Eduardo Nhamahanga ${ }^{4}$, Richard H Hunt ${ }^{1,2}$, Maureen Coetzee ${ }^{1,2^{*}}$
}

\begin{abstract}
Background: The dual problems of rising insecticide resistance in the malaria vectors and increasing human malaria cases since 2001 in southern Mozambique are cause for serious concern. The selection of insecticides for use in indoor residual spraying (IRS) programmes is highly dependent on the extent to which local mosquitoes are susceptible to the approved classes of insecticides. The insecticide resistance status and role in malaria transmission of Anopheles funestus was evaluated at the Maragra Sugar Estate in southern Mozambique where an IRS vector control programme has been in operation for seven years using the carbamate insecticide bendiocarb.
\end{abstract}

Results: No Anopheles species were captured inside the sugar estate control area. Anopheles funestus group captured outside of the estate represented $90 \%(n=475)$ of the total collections. Of the specimens identified to species by PCR ( $n=167), 95 \%$ were An. funestus s.s. One An. rivulorum was identified and seven specimens did not amplify. The Anopheles gambiae complex was less abundant $(n=53)$ and of those identified $(n=33) 76 \%$ were An. arabiensis and 24\% An. merus. Insecticide susceptibility tests showed that wild-caught and F-1 family An. funestus were resistant to deltamethrin (32.5\% mortality) and lambda-cyhalothrin (14.6\% mortality), less so to bendiocarb (71.5\% mortality) and fully susceptible to both malathion and DDT (100\%). Bendiocarb and pyrethroid resistance was nullified using 4\% piperonyl butoxide (Pbo), strongly suggesting that both are mediated by P450 monooxygenase detoxification. ELISA tests of An. funestus for Plasmodium falciparum, gave a sporozoite rate of $6.02 \%(n=166)$. One unidentified member of the An. gambiae complex tested positive for $P$. falciparum sporozoites.

Conclusion: Anopheles funestus was found to be the most abundant and principle vector of malaria in this area, with members of the An. gambiae complex being secondary vectors. Despite the continual use of bendiocarb within the estate for seven years and the level of An. funestus resistance to this insecticide, the IVC programme is still effective against this and other Anopheles in that no vectors were found inside the control area. However, the Mozambique National Malaria Control Programme ceased the use of DDT and bendiocarb in this area of its operations in 2009, and replaced these insecticides with a pyrethroid which will increase insecticide resistance selection pressure and impact on control programmes such as the Maragra IVC.

\section{Background}

Malaria in the south of Mozambique is mesoendemic to hyperendemic and is a major medical and socioeconomic burden to the country and the primary cause of clinic outpatient attendance [1]. It impacts particularly on the morbidity and mortality of children $<5 \mathrm{yr}$ of

\footnotetext{
* Correspondence: maureenc@nicd.ac.za

'Malaria Entomology Research Unit, School of Pathology, Faculty of Health

Sciences, University of the Witwatersrand, Johannesburg, South Africa

Full list of author information is available at the end of the article
}

age. Virtually all the population of Mozambique (99\% of 20.8 million people) is at risk of malaria, with 3.4 million children $<5$ yrs being the most vulnerable [1]. Malaria is on the increase in Mozambique with 4 million cases in 2001 and 6 million cases in 2006. Plasmodium falciparum accounts for $90 \%$ of parasite infections and P. malariae and P. ovale for $9 \%$ and $1 \%$ respectively [1].

Malaria control using indoor residual spraying (IRS) started in Mozambique in 1946, using DDT and Benzene Hexachloride (BHC) and stopped in 1956, with

\section{Biomed Central}


good results in reducing parasite and spleen rates in children $<5$ yrs during that period. Control actions were initiated again in 1960 using DDT as part of a malaria eradication programme and continued through to 1971 , when malaria control operations were limited to main towns due to civil war. By 1980 malaria control activities were confined to the Maputo area. A limited control action was again initiated in 1994 to evaluate lambdacyhalothrin, deltamethrin, baythroid and cyfluthrin insecticides, all pyrethroids or derivatives of pyrethrum. Lambda-cyhalothrin was selected as the insecticide of choice at that time (reviewed by Casimiro [2]).

In October 1999 the first commercial integrated malaria vector control (IVC) programme in Mozambique was implemented at the Mozal aluminium smelter in the Beluluane district of Maputo, creating a buffer zone of $1.6 \mathrm{~km}$ (1mile) around the smelter as proposed by Charlwood et al. [3] initially using deltamethrin (RGK, unpublished data). In early 2000 an insecticide resistance study was carried out on Anopheles funestus at the Mozal site [4]. This was the first insecticide resistance study to be carried out in Mozambique and $A n$. funestus proved to be resistant to both deltamethrin and lambda-cyhalothrin. Deltamethrin was replaced by the carbamate insecticide bendiocarb on the basis of vector susceptibility to this insecticide, it's acceptability for use in both western and traditional structures, and its nonrepellency of mosquitoes. Shortly thereafter, following this work at Mozal, the Mozambique National Malaria Control Programme (MNMCP) under the auspices of the Lubombo Spatial Development Initiative (LSDI), also changed from pyrethroid insecticides to bendiocarb for IRS in southern Mozambique, and has continued to do so, with the addition of DDT for IRS in 2006 [5,6].

The IVC programme at Maragra Sugar Estate, $90 \mathrm{~km}$ north of the capital city Maputo, started in 2002. It encompasses the central estate residential and factory areas and the rural area within a radius of $1.6 \mathrm{~km}$ from the centre of the estate residential area, creating a barrier effect or cordon sanitaire around the target estate residential and mill areas. Due to the endophily and endophagy of $A n$. funestus, the IVC management programme consists of a four month cycle of IRS with bendiocarb, to all homes, offices and factory, monthly IRS of the factory itself and fortnightly ultra-low-volume (ULV) spraying of the factory with the organophosphate insecticide dichlorvos to knockdown predominantly Culex spp. of mosquitoes. This escalation of IRS and ULV to the factory is due to the factory operating on a 24 hour basis during the harvesting and milling of the cane. Within the estate itself a programme of repairing and refurbishing drains and septic tanks and their covers is in place. Mosquito nets are provided to employees and their families on a voluntary and subsidized basis.
The nets are not impregnated with a pyrethroid due to the high levels of pyrethroid resistance in the malaria vectors. Health education on personal protection measures, life cycle and habits of vector mosquitoes and the need for early diagnosis and treatment at the company and government clinic, is carried out on an informal and formal basis to expatriate and local people within the estate control area. Diagnosis by microscopy is carried out on all employees and expatriate family members presenting with symptoms, and treatment with an ACT is given on a positive slide diagnosis.

In the light of increased usage of pyrethroids by the MNMCP and the dropping of bendiocarb for IRS (http://www.rollbackmalaria.org/countryaction/mozambique_roadmap.html, 2009-2010), a survey was initiated to find out the level of resistance to pyrethroids and bendiocarb in the Maragra area.

\section{Materials and methods \\ Study area}

Maragra sugar estate is situated in the Maputo province of Mozambique $\left(25^{\circ} 27^{\prime} \mathrm{S}, 32^{\circ} 46^{\prime} \mathrm{E}\right), 90 \mathrm{~km}$ north of Maputo city, $3 \mathrm{~km}$ south of Manhica town and approximately $10 \mathrm{~km}$ inland from the Indian Ocean (Figures 1, 2). It is surrounded on all but the east side by three rural villages forming one single unit with a population of \pm 20,000. The number of Maragra estate employees fluctuates between 1,250 and 4,500 personnel per month through the year, with a significant increase in personnel from April through to November/December, when the harvesting and milling of the cane takes place. These personnel are drawn from the surrounding villages and other rural areas.

\section{Adult mosquito collections}

The field site at Maragra was visited for two weeks per month from January to March 2009. Mosquitoes were sampled by indoor house searches, knock down collections, window exit traps, natural shelters and pit traps from areas inside and outside the sugar estate control

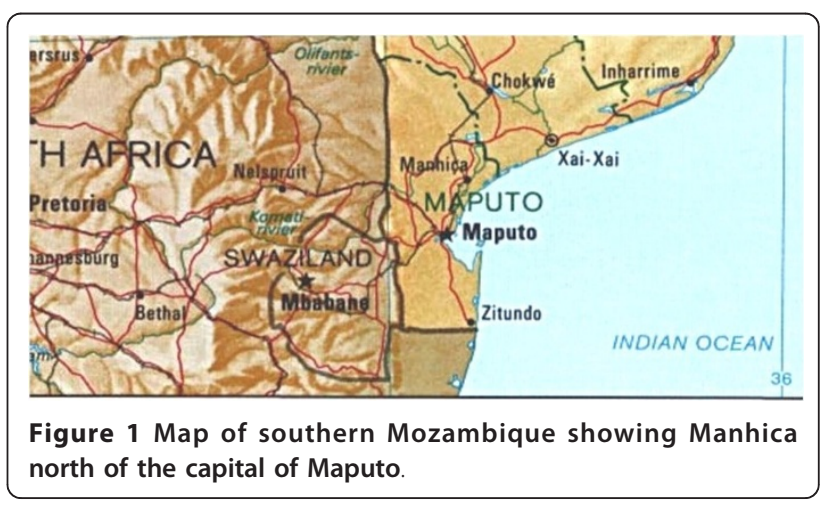




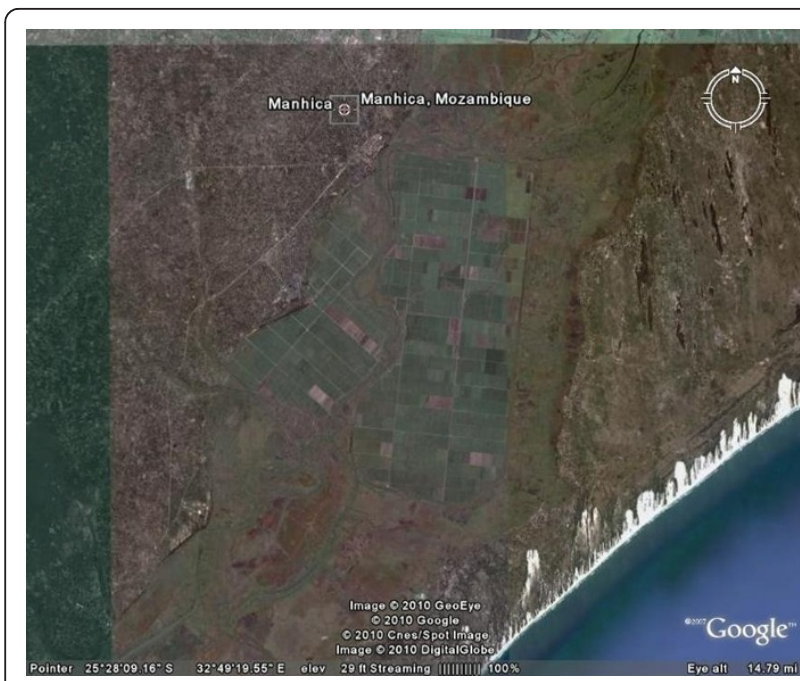

Figure 2 Google Earth map showing the Maragra sugar estate south of Manhica in southern Mozambique.

operations. Live female $A n$. funestus group and $A n$. gambiae complex mosquitoes were placed in polystyrene cups and transported back to the Vector Control Reference Unit (VCRU) insectary at the National Institute for Communicable Diseases (NICD), Johannesburg. Subsequently, females were tubed individually for egg-laying and the egg batches reared under standard conditions to obtain F-1 adult progeny.

\section{Species identification}

Captured mosquitoes were initially identified to group by morphology [7]. PCR methods for the An. funestus group [8] and $A n$. gambiae complex [9] were used to identify the species in each group. Extraction of DNA [10] was done for the An. funestus group, and direct homogenization of a single leg for the An. gambiae complex.

\section{ELISA for P. falciparum parasites}

Vector mosquitoes collected from an unsprayed area outside of the Maragra estate were assayed by enzymelinked immunosorbent assay (ELISA) to investigate their Plasmodium falciparum sporozoite infection rate. This assay entailed homogenizing the mosquito head and thorax and measuring the P. falciparum circumsporozoite (CS) protein levels [11].

\section{Insecticide Susceptibility}

Insecticide susceptibility bioassays were carried out on both wild caught and F1 generation mosquitoes to the four classes of approved public health insecticides, according to the standard WHO operating procedure [12]. Insecticides tested were: 4\% DDT (organochlorine), $5 \%$ malathion (organophosphate), $0.1 \%$ bendiocarb and $0.1 \%$ propoxur (carbamates) and $0.05 \%$ deltamethrin and $0.05 \%$ lambda-cyhalothrin (pyrethroids). Bioassays were also conducted on bendiocarb and deltamethrin without and with the synergist piperonyl butoxide (4\% Pbo).

Wild-caught females and 2-5 day old F-1 progeny were exposed to insecticide treated papers for one hour. Knockdown was recorded at the end of the exposure period and 24 hour mortality the following day. Between two and nine replicates per insecticide were performed dependent upon available mosquitoes, with an emphasis on bendiocarb as this is the insecticide in use on the estate at present. Controls were not exposed to any insecticide. The WHO insecticide treated papers were tested for efficacy by exposing a susceptible reference strain (An. gambiae SUA) to them in the same manner as for the exposed mosquitoes.

The Pbo experiments were conducted on 2-4 day old F-1 females. Mosquitoes were exposed to $4 \%$ Pbotreated papers for one hour prior to exposure to deltamethrin and bendiocarb. Controls were exposed to Pbo only. Knockdown was recorded at the end of the one hour exposure and again at 24 hours for final mortality.

\section{Results}

\section{Wild Mosquito Collections}

A total of 528 wild caught vector mosquitoes were collected from the study site over the period January to April 2009 (Table 1). Anopheles funestus group was dominant in the collections $(90 \%, \mathrm{n}=475)$ with the $A n$. gambiae complex being present in very low numbers $(10 \%, \mathrm{n}=53)$.

Indoor house searches proved to be the most successful method with the majority of both An. funestus group and $A n$. gambiae complex found resting indoors in

Table 1 Anopheles funestus and An. gambiae s.l. collection methods and species identifications

\begin{tabular}{|c|c|c|c|c|c|}
\hline Method & An. funestus & An. rivulorum & An. gambiae s.l. & An. arabiensis & An. merus \\
\hline Indoor Resting & 439 & 1 & 38 & 25 & 8 \\
\hline Window Trap & 9 & 0 & 5 & - & - \\
\hline Knockdown & 26 & 0 & 10 & - & - \\
\hline Natural Shelters \& Pit Traps & 0 & 0 & 0 & 0 & 0 \\
\hline Total & 474 & 1 & 53 & 25 & 8 \\
\hline
\end{tabular}


unsprayed houses outside of the Maragra control area. Knockdown catches and window exit traps were not as effective, particularly for An. funestus. Indoor searches, knockdown catches and window traps in sprayed houses within the Maragra IVC resulted in no collections of vector mosquitoes resting indoors. Natural shelters and pit traps were entirely unsuccessful in the collection of vector mosquitoes, but highly successful for the collection of Culex spp. It was evident from this collection technique that both An. funestus group and An. gambiae complex do not utilise such refuges in this area.

\section{Species identification}

A total of 175/475 (36\%) of the An. funestus group and 52/53 (98\%) of the An. gambiae complex were tested by PCR to establish species-specific identification. The majority of the An. funestus group samples were identified as An. funestus s.s. $(95 \% ; \mathrm{n}=167)$ and one specimen identified as An. rivulorum. Only 33/52 of the $A n$. gambiae complex samples gave amplified products and of these $75.8 \%(\mathrm{n}=25)$ were identified as An. arabiensis and $24.2 \%(\mathrm{n}=8)$ as An. merus. The lack of PCR products from 19 samples could have been due to DNA degradation through poor storage in the field.

\section{ELISA assays for $\mathrm{P}$. falciparum parasites}

A total of 166 An. funestus samples were subjected to the ELISA test for Plasmodium falciparum circumsporozoite (CS) protein. Ten specimens were confirmed positive after retesting, giving a positivity rate of $6.02 \%$ for An. funestus in the areas outside of the Maragra IVC zone. The ELISA tests conducted on 52 An. gambiae complex samples gave one confirmed positive, i.e. $1.9 \%$. Unfortunately, this specimen was not identified to species as it did not amplify on PCR.

\section{Insecticide resistance}

Due to low numbers of the An. gambiae complex collected on a daily basis, insufficient females survived for egg-laying, and of those that did, oviposition was not successful. As a result no insecticide resistance assays could be carried out on this group of species.

A total of 952 An. funestus wild-caught and F-1 generation females (including controls) were used in the tests for susceptibility to the four classes of insecticides. The results are summarised in Table 2. Given that 99.4\% of all PCR identified samples were An. funestus s. $s$., it is assumed that the results from this section pertain to this species. A total of 261 wild caught An. funestus were tested for susceptibility on the same day they were collected. The highest levels of resistance were found to lambda-cyhalothrin $(14.6 \%$ mortality $24-\mathrm{hr}$ postexposure) and deltamethrin (32.5\% mortality) (Table 2). According to $\mathrm{WHO}$ criteria, resistance to bendiocarb
Table 2 Insecticide susceptibility of Anopheles funestus s.s. from Maragra, Mozambique

\begin{tabular}{ccccc}
\hline Insecticide & \multicolumn{2}{c}{ Wild-caught } & \multicolumn{2}{c}{$\begin{array}{c}\text { 2-5 day old F-1 } \\
\text { progeny }\end{array}$} \\
\hline & $\begin{array}{c}\text { No. } \\
\text { Exposed }\end{array}$ & $\begin{array}{c}\% \\
\text { Mortality }\end{array}$ & $\begin{array}{c}\text { No. } \\
\text { Exposed }\end{array}$ & $\begin{array}{c}\% \\
\text { Mortality }\end{array}$ \\
\hline 0.05\% Deltamethrin & 37 & 32.5 & 156 & 52.6 \\
\hline $\begin{array}{c}\text { 0.05\% } \\
\text { Lambdacyhalothrin }\end{array}$ & 35 & 14.6 & 54 & 33.3 \\
\hline 0.1\% Bendiocarb & 117 & 71.2 & 76 & 72.4 \\
\hline 4\% DDT & 20 & 100 & 61 & 100 \\
\hline 5\% Malathion & 52 & 100 & 52 & 100 \\
\hline
\end{tabular}

with $71.2 \%$ mortality in the wild caught population was confirmed. Using F-1 generation females, similar low mortalities were found for pyrethroids and bendiocarb (Table 2). The Chi-square values for comparisons between the wild samples and the F-1 generation $2-5$ day old mosquitoes were deltamethrin 5.15 ( $\mathrm{p}<$ $0.05)$, lambda-cyhalothin $3.94(\mathrm{p}<0.05)$ and bendiocarb 0.11 ( $p>0.05)$. This indicates that at least for the pyrethroids there is a significant difference in survival between wild-caught mosquitoes and the F-1 laboratory reared progeny, with wild-caught females surviving better on exposure to pyrethroids. Both DDT and malathion gave $100 \%$ mortality (Table 2 ).

Those F-1 families producing enough adults for subsequent analysis were assayed either individually or pooled against the monooxygenase inhibitor Pbo and the insecticides bendiocarb and deltamethrin (Table 3). In all samples $100 \%$ susceptibility to bendiocarb was achieved with the Pbo and $92.6 \%$ to deltamethrin. The deltamethrin results are in agreement with previous studies $[4,13]$ while the bendiocarb results strongly suggest monooxygenase detoxification as well.

\section{Discussion}

While IRS within the Maragra IVC zone has been very effective in controlling both the An. funestus group and the An. gambiae complex, circulating adults of these species may be responsible for those malaria cases presenting within the IVC zone. Although the bendiocarb resistance in the wild populations of An. funestus around Maragra is cause for concern, spraying the $1.6 \mathrm{~km}$ buffer zone (as recommended by [3] and [14]) with this insecticide appears to be exerting an effective control influence as no vectors were found resting indoors or collected in houses from the IVC area. In contrast, all mosquitoes collected during this study were found outside the Maragra IVC area, with indoor resting An. funestus being the most common vector present.

The results of the insecticide bioassay trials reflect a similar pattern of resistance to pyrethroids and carbamates 
Table 3 Percent mortality of Piperonyl butoxide (Pbo) synergised and unsynergised F-1 samples of Anopheles funestus from Maragra, Mozambique.

\begin{tabular}{|c|c|c|c|c|c|c|c|}
\hline & Pooled F-1 & Family No. 19 & Family No. 23 & Family No. 32 & Family No. 39 & Family No. 42 & Family No. 58 \\
\hline $0.1 \%$ Bendiocarb & $\begin{array}{l}72.2 \\
(18) \\
\end{array}$ & $\begin{array}{c}77.7 \\
(9) \\
\end{array}$ & $\begin{array}{c}100 \\
(6) \\
\end{array}$ & $\begin{array}{r}62.5 \\
(8) \\
\end{array}$ & $\begin{array}{l}57 \\
(7)\end{array}$ & $\begin{array}{c}83 \\
(12) \\
\end{array}$ & $\begin{array}{l}62.5 \\
(16) \\
\end{array}$ \\
\hline $4 \% \mathrm{Pbo}+0.1 \%$ Bendiocarb & $\begin{array}{l}100 \\
(19)\end{array}$ & $\begin{array}{l}100 \\
(10)\end{array}$ & $\begin{array}{c}100 \\
(9)\end{array}$ & $\begin{array}{l}100 \\
(8)\end{array}$ & $\begin{array}{l}100 \\
(7)\end{array}$ & $\begin{array}{l}100 \\
(12)\end{array}$ & $\begin{array}{l}100 \\
(16)\end{array}$ \\
\hline 0.05\% Deltamethrin & $\begin{array}{c}50 \\
(42)\end{array}$ & - & - & - & - & - & - \\
\hline $4 \% \mathrm{Pbo}+0.05 \%$ Deltamethrin & $\begin{array}{l}92.6 \\
(27)\end{array}$ & - & - & - & - & - & - \\
\hline Controls 4\% Pbo only & $\begin{array}{c}0 \\
(184)\end{array}$ & & & & & & \\
\hline
\end{tabular}

Sample sizes in parenthesis.

that has already been reported for southern African populations of $A n$. funestus [5,15]. The results for the WHO susceptibility tests on wild female mosquitoes of unknown age when compared with 2-5 day old F-1 laboratory reared progeny, revealed that there is a statistically significant survival of wild (i.e. older) mosquitoes. This is in contrast to Anopheles gambiae s.s. where higher frequencies of resistance are expected in younger mosquitoes because of the fitness cost to older mosquitoes carrying the resistance genes [16].

Aranda et al. [17] surveyed the vector populations in the Manhica area from October 1997 to September 1998 and reported peak $P$. falciparum sporozoite rates of $5 \%$ in November and $>2 \%$ in May. These rates are slightly lower than those reported in this study (6\%), which was carried out during the mid to latter part of the rainy season (January to March). However, their main method of collection was different in that CDC light traps were used which may have attracted a different segment of the population to those collected passively resting inside houses in the present study. What is apparent, however, in comparing the two studies, is that the MNMCP operations in this area have had very little impact on the vector populations over the past 11 years.

Further investigations need to be done with regard to the breeding sites and role of malaria transmission of the An. gambiae complex in this area. A recent study carried out in Boane, outside the capital Maputo, showed that $A n$. merus can play a significant role in malaria transmission in this region [18], this being the first record from southern Africa. Many searches for larval habitats have been carried out in the Maragra area in the past without success (RGK personal observations). Salt from the sea during the Cretaceous, Miocene and Pliocene times [19] may have leached to the surface due to the irrigation practices in these areas, creating suitable saltwater breeding sites for $A n$. merus. However, $A n$. merus has previously been found in the same freshwater bodies as other members of the An. gambiae complex, albeit far inland [20,21], so saltwater habitats are not necessarily a pre-requisite for this species.

Mayor et al. [22] reported that almost half of the human adult population from Manhica town were positive for $P$. falciparum during the dry season, and that rates may be even higher in the wet season. Mabunda et al. [23] reported human malaria parasite prevalence of $58.9 \%$ of which $52.4 \%$ were due to P. falciparum, the burden being in the northern areas and also the coastal areas, where Maragra is situated. The high sporozoite rates found in An. funestus in this study would support findings on high levels of parasitaemia in the human populations.

Despite the use of bendiocarb, lambda-cyhalothrin and DDT in the areas outside of the Maragra IVC, personal observations showed that not all the dwellings had been sprayed, and in many instances those that had been sprayed were not done so in accordance with WHO guidelines on IRS [24]. Insecticide deposits on the walls were erratic in concentration and distribution over substrates and dwellings (RGK, personal observations). Partial explanation for this may be due to the subsistence agricultural activities of the community. People are tending to their fields very early in the morning to escape the heat later in the day. When the spray teams arrive they often find locked homes, or the head of the household is not present and, due to local custom, entrance to the dwellings is denied by other members of the family. Supervision of the spray schedules and follow up on IRS coverage may also be lacking in some aspects. The integrity of the spray programme is then compromised to the detriment of the malaria control efforts [25,26].

An added problem is the leakage of insecticides from government storage facilities [27] and the use of these in domestic households or by subsistence farmers in agriculture. These issues, together with the uneven and erratic IRS coverage mentioned above, are almost certainly exerting strong selective pressure on the $A n$. funestus populations. The vector control operations that 
are ongoing outside of the Maragra IVC area are obviously not having any positive impact on malaria transmission, given the $6 \%$ sporozoite rate in $A n$. funestus. Continued monitoring and urgent improvement of this situation is critical to the success of both the Maragra IVC and the MNMCP as the arsenal of new, available and acceptable insecticides is extremely limited $[28,29]$. Moreover, the recent policy decision by Mozambique to use only lambda-cyhalothrin for IRS [27] should be reconsidered in the light of the results presented here and by earlier research [4-6].

\section{Conclusions}

The success of the Maragra IVC programme is due in large part to a 'captured population' where spraying of all dwellings, offices and the mill is mandatory and adheres to a four monthly cycle of IRS. This includes the surrounding village areas falling within the $1.6 \mathrm{~km}$ buffer zone, compliance being ensured by the chief of the particular area. There are financial implications of this strategy to the sugar estate, but they are outweighed by the low levels of malaria disease burden and increased health of the community and workforce. In this instance, Maragra is implementing a leading and excellent corporate and social obligation and responsibility to its employees and the surrounding local community, through sustainable control of malaria and its vectors.

\section{Acknowledgements}

Maragra (Illovo) sugar estate management is thanked for their support during this project. Staff and students of the Vector Control Reference Unit, NICD, are thanked for their assistance in training RGK in laboratory techniques. Partial funding was provided by the Department of Science and Technology and National Research Foundation SARChl grant to MC.

\section{Author details}

${ }^{1}$ Malaria Entomology Research Unit, School of Pathology, Faculty of Health Sciences, University of the Witwatersrand, Johannesburg, South Africa. ${ }^{2}$ Vector Control Reference Unit, National Institute for Communicable Diseases, National Health Laboratory Service, Private Bag X4, Sandringham, Johannesburg 2131, South Africa. ${ }^{3}$ Foray Consultants, P.O. Box 383, Hillcrest, 3650, KwaZulu-Natal, South Africa. ${ }^{4}$ Maragra (Illovo) Sugar Estate, Manhica, Mozambique.

\section{Authors' contributions}

RGK carried out the study, processed the specimens and drafted the manuscript. EN assisted with the field work and specimen collection and processing. $\mathrm{RHH}$ and $\mathrm{MC}$ designed the study, assisted with analysis of the data and helped draft the manuscript.

\section{Competing interests}

The authors declare that they have no competing interests.

Received: 3 November 2010 Accepted: 9 February 2011 Published: 9 February 2011

\section{References}

1. World Health Organization: World Malaria Report. Geneva, Switzerland; 2008.
2. Casimiro S: Susceptibility and Resistance to Insecticides Among Malaria Vector Mosquitoes in Mozambique. University of KwaZulu/Natal, MSc Thesis, South Africa; 2003.

3. Charlwood JD, Mendis C, Thompson R, Begtrup K, Cuamba N, Dgedge M, Gamage-Mendis A, Hunt RH, Sinden RE, Høgh B: Cordon sanitaire or laissez faire: differential dispersal of young and old females of the malaria vector Anopheles funestus Giles (Diptera: Culicidae) in southern Mozambique. Afr Entomol 1998, 6:1-6.

4. Brooke BD, Kloke G, Hunt RH, Temu EA, Koekemoer LL, Taylor ME, Coetzee M: Bioassay and biochemical analyses of insecticide resistance in southern African Anopheles funestus. Bull Entomol Res 2001, 91:265-272.

5. Casimiro S, Hemmingway J, Sharp BL, Coleman M: Monitoring the Operational Impact of Insecticide Usage for Malaria Control on Anopheles funestus from Mozambique. Malar J 2007, 6:142.

6. Coleman M, Casimiro S, Hemingway J, Sharp B: Operational impact of DDT reintroduction for malaria control on Anopheles arabiensis in Mozambique. J Med Entomol 2008, 45:885-890.

7. Gillies MT, Coetzee M: A Supplement to the Anophelinae of Africa South of the Sahara. Publications of the South African Institute of Medical Research, no. 55, Johannesburg, South Africa; 1987.

8. Koekemoer LL, Kamau L, Hunt RH, Coetzee M: A cocktail polymerase chain reaction assay to identify members of the Anopheles funestus (Diptera: Culicidae) group. Am J Trop Med Hyg 2002, 66:804-811.

9. Scott JA, Brogdon WG, Collins FH: Identification of single specimens of the Anopheles gambiae complex by the polymerase chain reaction. Am J Trop Med Hyg 1993, 49:520-529.

10. Collins F, Mendez AM, Rasmussen MO, Mehaffey CF, Besansky NJ, Finnerty $\mathrm{V}$ : A ribosomal RNA gene probe differentiates members of the Anopheles gambiae complex. Am J Trop Med Hyg 1987, 37:37-41.

11. Wirtz RA, Zavala F, Charoenvit Y, Campbell GH, Burkot TR, Schneider I, Esser KM, Beaudoin RL, Andre RG: Comparative testing of Plasmodium falciparum sporozoite monoclonal antibodies for ELISA development. Bull Wld HIth Org 1987, 65:39-45.

12. World Health Organization: Test procedures for Insecticide Resistance Monitoring in Malaria Vectors, Bio-Efficacy and Persistence of Insecticides on Treated Surfaces. 1998, WHO/CDS/CPC/MAL/98.12.

13. Wondji CS, Irving H, Morgan J, Lobo N, Collins FH, Hunt RH, Coetzee M, Hemingway J, Ranson H: Two duplicated P450 genes are associated with pyrethroid resistance in Anopheles funestus, a major malaria vector. Genome Res 2009, 19:452-459.

14. Mendis C, Jacobsen JL, Gamage-Mendis A, Bule E, Dgedge M, Thompson R, Cuamba N, Barreto J, Begtrup K, Sinden RE, Høgh B: Anopheles arabiensis and An. funestus are equally important vectors of malaria in Matola coastal suburb of Maputo, southern Mozambique. Med Vet Entomol 2000, 14:171-180.

15. Hargreaves K, Koekemoer LL, Brooke BD, Hunt RH, Mthembu J, Coetzee M: Anopheles funestus is resistant to pyrethroid insecticides in South Africa. Med Vet Entomol 2000, 14:181-189.

16. Lines JD, Nassor NS: DDT resistance in Anopheles gambiae declines with mosquito age. Med Vet Entomol 1991, 5:261-265.

17. Aranda C, Aponte JJ, Saute F, Asimiro S, Pinto J, Sousa C, Rosario V, Petrarca $V$, Dgedge M, Alonso P: Entomological characteristics of malaria transmission in Manhica, a rural area in southern Mozambique. J Med Entomol 2005, 42:180-186.

18. Cuamba N, Mendis C: The role of Anopheles merus in malaria transmission in an area of southern Mozambique. J Vector Borne Dis 2009 46:157-159.

19. Maud RR: The climate and geology of Maputaland. 1-7. The ecology, overwintering and population dynamics of the pre-imaginal stages of the Anopheles gambiae Giles complex (Diptera: Culicidae) in northern Natal, South Africa University of KwaZulu/Natal, PhD Thesis; 1991, 1980. In: Le Sueur D South Africa.

20. Coetzee M, Hunt RH, Braack LEO, Davidson G: Distribution of mosquitoes belonging to the Anopheles gambiae complex, including malaria vectors, south of latitude $15^{\circ} \mathrm{S}$. Sth Afr J Sci 1993, 89:227-231.

21. Kloke RG: New distribution record of Anopheles merus Donitz (Diptera: Culicidae) in Zambia. Afr Entomol 1997, 5:361-362.

22. Mayor A, Aponte JJ, Fogg C, Saùte F, Greenwood B, Dgedge M Menendez C, Alonso PL: The epidemiology of malaria in adults in a rural area of southern Mozambique. Malar J 2007, 6:3. 
23. Mabunda S, Casimiro S, Quinto L, Alonso P: A country-wide malaria survey in Mozambique.1. Plasmodium falciparum infection in children in different epidemiological settings. Malar J 2008, 7:216.

24. World Health Organization: Indoor residual spraying: Use of indoor residual spraying for scaling up global malaria control and elimination: WHO Position Statement. Geneva; 2006, WHO/HTM/2006.1112.

25. Townson $H$, Nathan MB, Zaim M, Guillet $P$, Manga L, Bos R, Kindhauser M: Exploiting the potential of vector control for disease prevention. Bull WId Hlth Org 2005, 83:942-947.

26. Beier JC, Keating J, Githure JI, Macdonald MB, Impoinvil DE, Novak RJ: Integrated vector management for malaria control. Malar J 2008, 7(supplement 1):54.

27. Presidents Malaria Initiative: Malaria Operational Plan - FY 09, Mozambique. 2009, 19-20.

28. Hemingway J, Beaty BJ, Rowland M, Scott TW, Sharp B: The Innovative Vector Control Consortium: improved control of mosquito-borne diseases. Trends Parasitol 2006, 22:308-312.

29. Tren R, Hess K, Bate R, Urbach J, Roberts D: Bias and Neglect: Public Health Insecticides \& Disease Control. 2008 [http://fightingmalaria.org].

doi:10.1186/1756-3305-4-16

Cite this article as: Kloke et al: Vectorial status and insecticide resistance of Anopheles funestus from a sugar estate in southern Mozambique. Parasites \& Vectors 2011 4:16.

\section{Submit your next manuscript to BioMed Central} and take full advantage of:

- Convenient online submission

- Thorough peer review

- No space constraints or color figure charges

- Immediate publication on acceptance

- Inclusion in PubMed, CAS, Scopus and Google Scholar

- Research which is freely available for redistribution

Submit your manuscript at www.biomedcentral.com/submit 